\title{
ASPECTOS CULTURAIS ASSOCIADOS ÀS MINHOCAS NO BRASIL
}

\author{
Gustavo Schiedeck, ${ }^{1}$ José Ernani Schwengber, ${ }^{1}$ Joel Henrique Cardoso, ${ }^{1}$ \\ Márcio de Medeiros Gonçalves ${ }^{2}$ \& Greice de Almeida Schiavon ${ }^{3}$ \\ ${ }^{1}$ Estação Experimental Cascata, Embrapa Clima Temperado, BR 392, km 78, 96001-970, CP 403, \\ Pelotas, Rio Grande do Sul, Brasil. e-mail: gustavo.schiedeck@cpact.embrapa.br \\ 2 Programa de Pós-graduação em Sistemas de Produção Agrícola Familiar, Universidade Federal de \\ Pelotas, Capão do Leão, Rio Grande do Sul, Brasil. e-mail: marciogoncalves@epagri.sc.gov.br \\ ${ }^{3}$ Curso de Bacharelado em Ecologia, Universidade Católica de Pelotas, Pelotas, Rio Grande do Sul, \\ Brasil. e-mail: greice_grapes@yahoo.com.br
}

Schiedeck, G., J. E. Schwengber, J. H. Cardoso, M. de M. Gonçalves, G. de A. Schiavon. 2010. Aspectos culturais associados às minhocas no Brasil. Acta Zoológica Mexicana (n.s.), Número Especial 2: 19-33.

RESUMO. Os oligoquetas fascinam os pesquisadores há muito tempo, porém, no Brasil, poucos sabem a origem do nome comum dado ao animal com que trabalham diariamente: 'minhoca'. Da mesma forma, o 'mito do minhocão' surge no imaginário popular do brasileiro do interior como um personagem da natureza capaz de provocar medo, respeito e admiração. $O$ trabalho procurou resgatar estes elementos por meio de consultas bibliográficas e pela rede mundial de computadores com o objetivo de preservar o legado cultural que índios, africanos e europeus construíram sobre a figura da minhoca. Sobre a etimologia do vocábulo 'minhoca', duas hipóteses apresentam bons elementos para discussão: a africana e a sul-americana ou brasileira. Contudo, os textos recentes preferem informar sua origem como obscura ou incerta. O 'mito do minhocão' é encontrado em diversas regiões do país, em especial onde rios, lagoas e áreas alagadas são fatores de destaque. Em cada relato assume distintas formas e comportamentos, mas com maior freqüência é descrito como uma minhoca ou cobra de tamanho descomunal que costuma desbarrancar as margens dos rios e virar os barcos dos pescadores. $\mathrm{O}$ 'minhocão' também é visto por muitos como um defensor da natureza contra aqueles que agridem o ambiente.

Palavras chave: Etimologia, cultura, mitos, Oligochaeta.

Schiedeck, G., J. E. Schwengber, J. H. Cardoso, M. de M. Gonçalves, G. de A. Schiavon. 2010. Aspectos culturales asociados a las lombrices de tierra en Brasil. Acta Zoológica Mexicana (n.s.), Número Especial 2: 19-33.

RESUMEN. Los oligoquetos fascinan a los investigadores hace mucho tiempo, pero en Brasil poco se sabe sobre el origen de su nombre común, 'minhoca'. Igualmente, el mito del 'minhocão' surge en el imaginario popular del brasileño del interior como un personaje de la naturaleza capaz de provocar miedo, respeto y admiración. El estudio buscó rescatar estos elementos a través de una revisión de la bibliografía y usando la red mundial de computadores, con el objetivo de preservar el legado cultural

Recibido: 16/05/2008; aceptado: 08/01/2010. 
que indígenas, africanos y europeos construyeran sobre la imagen de la lombriz. Sobre la etimología del vocablo adoptado en Brasil (minhoca) para designar las lombrices, dos hipótesis presentan elementos interesantes para la discusión: una de origen africana y otra de origen americana o brasileña. A pesar de todo, los trabajos recientes prefieren informar el origen etimológico del nombre común como obscura e incierta. El mito de la lombriz gigante, el 'minhocão', es encontrado en distintas regiones del país, en especial donde hay ríos, lagunas y humedales. En cada relato la lombriz gigante asume distintas formas y comportamientos, pero con mayor frecuencia es descrita como una gran lombriz o víbora de proporciones descomunales, que derrumba las márgenes de los ríos y tumba las embarcaciones de pescadores. La lombriz gigante también es vista por muchos como un defensor de la naturaleza contra aquellos que contaminan las aguas y destruyen al medio ambiente.

Palabras clave: Etimología, cultura, mitos, Oligochaeta.

\section{INTRODUÇÃO}

As minhocas fascinam os homens há muito tempo, tanto por suas peculiaridades morfológicas e anatômicas quanto pelo papel que desempenham na natureza. Desde a antigüidade, a importância das minhocas já era reconhecida por gregos e egípcios (Minnich 1977, Righi 1997). Porém, coube a Charles Darwin, em seu trabalho "The formation of vegetable mould through the action of worms with observations on their habits", de 1881, dar às minhocas um lugar de destaque no processo de pedoturbação e ciclagem da matéria orgânica do solo (Feller et al. 2003).

Atualmente, cientistas do mundo todo pesquisam as minhocas com os mais diferentes objetivos: do seu uso como bioindicador da qualidade ambiental ao aproveitamento na transformação de resíduos orgânicos agrícolas e urbanos para geração de adubo, passando pelo seu uso na alimentação animal e humana até o desenvolvimento de cosméticos e fármacos para o tratamento de doenças.

Neste universo de ciência e tecnologia, muitas vezes perdem-se de vista outros aspectos importantes e que, por sua vez, estão estreitamente ligadas à forma como o ser humano compreende o mundo que o cerca e às estratégias pela busca em perpetuar esse conhecimento. Os saberes populares são transmitidos de geração à geração por meio de processos de memória coletiva, constituindo um corpo de conhecimento que, aliado à criatividade e experiências dos indivíduos, orientam sua "práxis" frente ao ambiente (Barahona 1987, Toledo 1991).

No Brasil, a origem da palavra 'minhoca' é desconhecida pela maioria das pessoas, inclusive pesquisadores dedicados à sua preservação ou aproveitamento. Da mesma forma, a minhoca é apropriada pela cultura popular do brasileiro do interior sob o 'mito do minhocão', também pouco conhecido do público em geral. Esse texto não tem a pretensão de fazer uma análise profunda sobre o assunto. É apenas uma tentativa de resgatar uma das múltiplas facetas em que a sociedade brasileira, caracterizada pelo pluralismo de etnias, se apropria de uma idéia ou de uma imagem simples como a 'minhoca' para construir um pouco de sua própria identidade cultural. 


\section{ETIMOLOGIA DA PALAVRA}

Os cientistas acreditam que possam existir cerca de 8000 espécies de minhocas no mundo (Fragoso et al. 1997) e toda essa diversidade exige um grande esforço dos especialistas em classificá-las de forma inequívoca. Entretanto, o conhecimento popular é bem menos exigente nesse sentido e as minhocas são adjetivadas e agrupadas de acordo com suas características externas, comportamento, origem ou local onde são encontradas. Dessa forma, são identificadas a vermelha-da-Califórnia (Eisenia fetida (Savigny 1826) ou E. andrei Bouché 1972), a minhoca mansa ou rabo de escova (Pontoscolex corethrurus (Müller 1857)), a gigante africana (Eudrilus eugeniae (Kinberg 1867)), minhoca-louca ou puladeira (Amynthas gracilis (Kinberg 1867) ou A. corticis (Kinberg 1867)), dentre outras. No entanto, poucas são as pessoas que questionam a origem da própria palavra 'minhoca'.

Em muitos idiomas, a palavra que designa minhoca está relacionada, de forma geral, ao seu habitat e à sua semelhança com os vermes. Em inglês, minhoca é 'earthworm' (verme da terra), em francês é 'ver de terre' (verme da terra), em espanhol 'lombriz de tierra' (lombriga da terra), em italiano é 'lombrico' (lombriga) e em alemão é 'regenwurm' (verme das chuvas). O termo 'verme', foi utilizado por Carl von Linné no século XVIII para classificar todo animal invertebrado não-artrópode, com simetria bilateral, entre os quais eram enquadradas as minhocas, as sanguessugas, a lombriga (Ascaris lumbricoides), a solitária (Taenia solium), além dos moluscos sem conchas e até mesmo as águas-vivas. Verme é uma palavra originária do Latim (vermis), que por sua vez era empregada para designar, de forma genérica, certos invertebrados como lombrigas, minhocas, larvas de alguns insetos e parasitas do corpo animal (Koehler 1959, Bueno 1974, Ferreira 2004).

Com o avanço da ciência e dos sistemas taxonômicos, a classificação proposta por Linné tornou-se obsoleta por sua imprecisão, ao ponto de, nos dias de hoje, 'verme' não ser considerado sequer um táxon. Não obstante, a palavra ainda é ampla e correntemente utilizada pela população para designar os animais de corpo alongado ou achatado, mole e glabro, sem apêndices articulados e patas.

Por sua vez, o termo 'lombriga', também originário do Latim (lumbricus), era mais específico em seu significado, sendo usado por seus falantes para designar apenas o parasito intestinal que leva seu nome ou também minhoca (Koehler 1959, Torrinha 1986, Houaiss et al. 2007).

A língua portuguesa, com mais de 215 milhões de falantes no mundo, é o quinto idioma mais falado no mundo e o terceiro no ocidente. Ao contrário das principais línguas ocidentais contemporâneas e apesar de ter suas raízes alicerçadas no Latim, é a única que, aparentemente, não vincula o nome genérico dos representantes da Classe Oligochaeta à morfologia vermiforme ou ao local em que é mais comumente encontrado. 
A busca da etimologia da palavra minhoca na língua portuguesa é mais complicada do que se pressupõe. Sua real origem é considerada controversa e obscura pelos autores mais recentes (Cunha 1986, Ferreira 2004, Houaiss et al. 2007).

\section{Origem africana}

As primeiras datações do vocábulo minhoca na língua portuguesa surgiram a partir do século XVI, ao redor de 1560, em um romance de Jorge Ferreira de Vasconcellos intitulado Ulíssipo (Cunha 1986, Houaiss et al. 2007). Logo, as minhocas deveriam ser designadas por outra palavra anteriormente a esse período. Entre o século XII e o século XVI, num período lingüístico conhecido como "português arcaico", as minhocas eram conhecidas pelos lusos pelo vocábulo 'lombriz' (Righi 1997), assim como é na Espanha nos dias de hoje.

O momento histórico indicado para o surgimento do vocábulo 'minhoca' e a substituição do termo 'lombriz' coincide com uma época em que os portugueses, de forma pioneira, iniciaram as grandes navegações. A expansão portuguesa começou a partir de 1415 com a tomada de Ceuta, no norte da África, e em 1487 toda a costa oeste do continente já havia sido navegada. Em 1483, o navegador português Diogo Cão tornou-se o primeiro europeu a chegar à foz do Rio Congo, ponto que estabelece a fronteira entre a República do Congo e Angola (Bueno 2006). Nesse contexto, a interação entre portugueses e angolanos pode ter sido a ponte para incorporação da palavra 'minhoca' ao vocabulário português.

Alguns indícios apontam que o termo 'minhoca' vem do Mbundu (Quimbundo ou Kibundu em português), uma língua da família Bantu, mais precisamente de Angola (Victoria 1958). O Quimbundo é uma língua de grande relevância social por ser a língua tradicional da capital do País, Luanda, e do antigo reino dos N'gola. É um idioma falado por cerca de 3 milhões de pessoas, sendo a segunda língua da Angola em termos de número de falantes e, ao mesmo tempo em que emprestou muitas palavras à língua portuguesa, também incorporou desta muitos vocábulos. Foi a primeira língua africana a ser estudada e traduzida na Europa e uma das que mais conviveu com o idioma português desde o século XVI (Ramos 1997).

Para alguns, 'minhoca' é um neologismo do Quimbundo para 'nioka' (ou ainda 'nhoka', 'nhoca' ou 'nkoka') em Angola, ou 'nyoka' em Moçambique, que significa em ambos os países cobra ou víbora (Alpers 2005, Ramos 1997, Katulembe 2008). Mesmo apresentando um vocabulário incompleto e precisando recorrer ao português em muitos casos, o Quimbundo, por outro lado, possui um vocábulo específico para designar 'verme' ou 'lombriga' que é a palavra 'ribuka'.

Em alguns endereços disponíveis na rede mundial de computadores destinados à língua Quimbundo, é possível encontrar variações e discrepâncias: enquanto em alguns a origem da palavra minhoca está no vocábulo 'kinhoka' (com K), que significa 
cobra comprida (Pinto 2008) ou simplesmente cobra ou serpente (Chaia 2006), em outros 'kinhoca (com C) é traduzido como 'fome' (Katulembe 2008). Não obstante, publicações de referência na língua portuguesa apresentam ainda outra etimologia, de origem quimbunda, para minhoca: 'munhoca' (Larousse 1999).

Toda essa complexidade pode estar relacionada à variedade lingüística original existente na África. Apenas em Angola há onze grupos lingüísticos, subdivididos em cerca de noventa dialetos, sendo as principais línguas: o umbundu, falado na parte central do país; o kikongo, falado ao norte; o chokwe-lunda e o kioko-lunda, no nordeste, além do próprio kimbundu, falado por grupos aparentados do litoral, incluindo a capital Luanda. Desta forma, para facilitar a comunicação entre as diferentes línguas nativas, o português tornou-se uma espécie de língua franca, promovendo e sofrendo modificações (Medeiros 2008).

Deve-se levar em conta também que, pouco após os contatos lingüísticos iniciais entre portugueses e africanos, os primeiros escravos negros foram levados para a Europa. Nesse contexto, a luta para aprender o idioma português sob condições desfavoráveis ocasionava distorções, que por sua vez ficou conhecida como "língua de preto" ou "fala da guiné". Nos agrupamentos de escravos não predominava uma língua em particular, sendo, por isso, difícil aferir a influência direta de uma língua em particular sobre o português. Assim, os primeiros vocábulos afro-portugueses apresentaram diferenças naturais decorrentes da sua origem, como por exemplo, o português gerado em Moçambique e o gerado em Angola (Lipski 2008a)

\section{Origem Sul-Americana ou Brasileira}

Embora a influência africana na língua portuguesa do Brasil seja incontestável, sobretudo na dimensão lexical (Lipski 2008b), a teoria da origem sul-americana da palavra minhoca também apresenta seus defensores.

A minhoca é um ser conhecido por diversos povos indígenas sul-americanos. De fato, alguns grupos indígenas até consomem, ou consumiam historicamente, minhocas como alimento (Paoletti \& Dufour 2005). Portanto, existem diversas palavras nas diferentes línguas nativas da América do Sul para designá-la (Tabela I).

Essas demonstram uma imensa variação morfológica e, conseqüentemente, fonética. De fato, uma só tribo da Amazônia Venezuelana (Ye'kuana), próxima à divisa com o Brasil, possui 16 etno-nomes para as minhocas (Paoletti \& Dufour 2005). Não obstante, por volta de 1500 , quando desembarcaram os primeiros colonizadores portugueses, o dialeto mais falado da "Língua Brasílica" no litoral era o Tupi (Tunes 2008).

Para os falantes do Tupi na época, a palavra usada para designar 'minhoca' era 'aboy'. De forma semelhante ao que ocorre no Quimbundo, 'aboy' (ou 'abói') deriva de 'mboy' (ou 'mboîa', 'mbói' ou 'moy') que por sua vez significa 'cobra' (Furtado 1969, Bueno 1987, Navarro 2008, Nicolai 2008, ilva 2008). 
Schiedeck et al.: Aspectos culturais das minhocas no Brasil

Tabela I. Transcrição ortográfica para o vocábulo 'minhoca' em diferentes línguas indígenas de diversas regiões do Brasil e da tribo Ye'kuana do Sul da Venezuela.

\begin{tabular}{|c|c|c|c|}
\hline Língua & Estado & Transcrição ortográfica & Referência \\
\hline kuikuro & Mato Grosso & Oto & Museu do Índio (2008); \\
\hline Kayabí & Mato Grosso e Pará & Ewa'it & $\begin{array}{l}\text { Instituto Socioambiental } \\
(2008)\end{array}$ \\
\hline Krahô & Tocantins & Kutõn & \\
\hline Yawalapíti & Mato Grosso & Uxinha & \\
\hline Munduruku & $\begin{array}{l}\text { Pará, Mato Grosso e } \\
\text { Amazonas }\end{array}$ & Nasen'pu & \\
\hline Karitiana & Rondônia & Gyryj & \\
\hline Umutina & Mato Grosso & Halomoty & \\
\hline Kamayurá & Mato Grosso & Wewa'it & \\
\hline Tukano & Noroeste da Amazônia & Ahũ̃ & \\
\hline$?$ & Acre & Chibui & Righi \& Guerra (1985) \\
\hline Caigange & Paraná, São Paulo & Panxin & Righi (1971) \\
\hline Maiongong & Roraima & Motu & Righi (1998) \\
\hline Pacaas-Novos & Rondônia & Emete & Righi \& Guerra (1985) \\
\hline Ye'kuana & Amazonas (Venezuela) & $\begin{array}{l}\text { Motto, kuru, saridi, sciciu, } \\
\text { mawada, takasu, tanaje, } \\
\text { daicik, vejaj, toccamo, } \\
\text { taegic, modoiddi, mouato, } \\
\text { araito, cetoka, kurujicette, }\end{array}$ & $\begin{array}{l}\text { Righi \& Araújo (1999) } \\
\text { Moreno \& Paoletti (2004) } \\
\text { Paoletti \& Dufour (2005) }\end{array}$ \\
\hline
\end{tabular}

Surpreende o fato de haver, segundo alguns autores, uma palavra 'minhoca' na língua Tupi. Conforme Teodoro Sampaio, importante geógrafo e historiador brasileiro do final do século XIX e início do século XX, o termo 'minhoca' derivava de 'mi-nhoca' ou 'mi-nhogá' (Victoria 1958), significando não o anelídeo em si, mas o verme que é extraído, arrancado ou tirado da terra (Bueno 1987). Contudo, estes vocábulos originais não foram localizados em nenhuma das outras obras consultadas ou endereços eletrônicos.

Apesar das dúvidas que existem sobre a raiz da palavra 'minhoca', as populações indígenas apresentaram uma contribuição, essa sim, inquestionável. Tal contribuição se deu na adjetivação das minhocas com o uso do elemento de composição '-uçu' ou '-açu' ('gwa'su' em Tupi ou sob as formas 'wa'su', 'a'su' e '-u'su'), que designa 
grande, vasto, considerável, formando o vocábulo 'minhocuçu' ou ainda 'minhocaçu' (Ferreira 2004, Houaiss et al. 2007), ou seja, "grande verme que é retirado ou extraído de terra". Outros textos utilizam a grafia 'minhocossu' ou 'minhocussu', fazendo referência ao fato do Tupi não possuir o sinal gráfico 'ç' (Bueno 1974). Desta forma, o substantivo masculino minhocuçu, como é mais utilizado, é um vocábulo tipicamente brasileiro e, de forma genérica, refere-se àqueles espécimes que apresentam diâmetro e comprimento muito superiores aos verificados nos espécimes mais comuns.

Há mais de 52 espécies de minhocuçus no Brasil; desse total apenas duas são da família Ocnerodrilidae enquanto o resto pertence à família Glossoscolecidae, principalmente aos gêneros Glossoscolex e Rhinodrilus (Brown \& James 2007). Destas, apenas 5 espécies possuem comprimento maior do que um metro, enquanto espécies com 30 a 50 centímetros são relativamente comuns. Embora minhocas com grandes dimensões sejam encontradas em todos os continentes, estas são, aparentemente, mais numerosas no Brasil (James \& Brown 2006).

A ocorrência de minhocas de grande tamanho em terras brasileiras nos primeiros séculos da ocupação, em oposição à verificada nos dias atuais em virtude da degradação ambiental, além de justificar o uso do adjetivo '-uçu' pelos falantes do Tupi, poderia também explicar a preexistência de um termo 'minhoca' no vocabulário indígena. Essa idéia ganha força a partir da análise da língua Guarani, que também era falada na costa litorânea brasileira e apresenta alguma semelhança com o Tupi, por pertencer à mesma família lingüística.

No idioma Guarani, dialeto Mbyá, 'minhoca' é designada por 'evo'i' ('aboy' em Tupi) e 'evo'i guaxu' é a expressão usada para minhocuçu ou minhocão; 'guaxu' ('gwa'su' em Tupi) representa a idéia de grande, sendo por isso um elemento gramatical usado apenas como determinante e não como predicado (Dooley 2006). Com isso, a tradução correta seria 'minhocão' ou 'minhocuçu' e não 'minhoca grande'.

Evidentemente, sem o estudo da datação do vocábulo, a possibilidade de existir a palavra 'minhoca' em Tupi fica apenas no terreno da especulação, já que o termo poderia ter sido gerado a partir do convívio entre índios e portugueses à partir do século XVI e daí se espalhado para a Europa.

\section{Outras hipóteses}

Um dos principais lingüistas e lexicógrafos portugueses, Aniceto dos Reis Gonçalves Viana, que viveu entre 1840 e 1914, defendia a hipótese da origem africana do vocábulo 'minhoca' (Bueno 1974). Contudo, o filólogo, historiador e bibliógrafo português José Pedro Machado discordava tanto da hipótese africana quanto da sulamericana, uma vez que a palavra 'minhoca' em meados do século XVI já era bem conhecida e documentada, inclusive em comédias escritas (Houaiss et al. 2007): seria pouco provável que, num prazo relativamente curto de tempo, o vocábulo pudesse ser internalizado e difundido pelo idioma Português naquela época. Desta forma, em 
algumas obras de referência, a etimologia da palavra 'minhoca' é citada apenas como controversa ou obscura (Ferreira 2004, Houaiss et al. 2007).

Apesar das hipóteses africanas e sul-americanas apresentarem argumentos interessantes para o debate, uma terceira possibilidade ainda é levantada: 'minhoca' seria formada pela conjunção de 'mina' e 'oca' ('min-oca'), com ressôo nasal na vogal 'i' ('mĩ-oca') e conseqüente palatização 'nh' e formação da palavra. O vocábulo 'mina' é originário do celta e denota o lugar onde são encontrados metais preciosos como ouro e prata, geralmente em depressões e a certa profundidade na terra. Por sua vez, 'oka' tem origem no Tupi e seu significado é a casa ou moradia usada pelos índios brasileiros. Por essa hipótese, a mais clara acepção do termo 'minhoca' seria: o verme que vive na terra ('oka') e em cujo interior abre galerias ('mina) (Bueno 1974). Neste contexto, a palavra 'minhoca' apenas poderia ter se originado no Brasil e a partir da convivência de portugueses e nativos falantes do tupi, ou seja, um vocábulo euro-brasileiro, da mesma forma que a sua variante 'minhocuçu'.

\section{O MITO DO MINHOCÃO}

O Brasil é um país continental e do qual muitas vezes se afirma comportar o mundo todo dentro de si, em alusão às diversas etnias que compõe sua população e, conseqüentemente, forjam sua própria identidade como nação. Num mosaico cultural formado por índios, negros, europeus, asiáticos e todas suas possíveis combinações, os mitos e lendas são incorporados ao imaginário popular de forma natural. Estes mitos e lendas, ao contrário do que muitos pensam, servem para que um povo possa dar significado às coisas que o rodeia, representar suas idéias e ser usado nos mais diversos contextos (Rocha 1996). O mito é um relato fantástico, em geral veiculado pela tradição oral e protagonizado por seres que, simbolicamente, representam as forças da natureza e os aspectos gerais da condição humana (Houaiss et al. 2007).

O mito do minhocão, embora pouco conhecido nas cidades, apresenta grande difusão no meio rural, em especial nas regiões onde a água de rios ou lagos tem destaque no contexto sócio-cultural de uma comunidade. Em diversas obras de referência, a consulta ao verbete 'minhocão' remete à descrição quase unânime de um ser fantástico, muito grande, que habita os lagos, açudes, banhados e rios, ora capaz de realizar milagres, outra de assustar viajantes, índios e pescadores, virando seus barcos ou provocando o desmoronamento dos barrancos dos rios (Bueno 1974, Cascudo 1984, Houaiss et al. 2007). Às vezes, o vocábulo também é identificado como sendo sinônimo de minhocuçu (Bueno 1987) ou cobra-cega (Ferreira 2004).

O botânico e naturalista francês, Auguste de Saint-Hilaire, que ao viajou pelo Brasil entre 1816 e 1822, ao passar por Minas Gerais e Goiás, entrevistou diversas pessoas, algumas muito respeitáveis segundo ele próprio, que confirmaram a existência do minhocão nos rios e lagoas da região (Cascudo 1984). O minhocão era descrito como um monstro de boca visível, negro, curto e de grande espessura, que vivia ex- 
clusivamente na água, nunca vinha à superfície e que desaparecia com bois e cavalos enlaçando-os por baixo do ventre. Inicialmente, Saint-Hilaire acreditou tratar-se de uma enguia elétrica do gênero Gymnotus, mas após algumas consultas relacionou o minhocão ao gênero Lepidorisen (Cascudo 2001), um peixe pulmonado conhecido no Brasil como pirambóia (do Tupi, 'pira'mboya') (Houaiss et al. 2007), com até 1,25 $\mathrm{m}$ de comprimento e capaz de sobreviver enterrado na lama durante as estações secas (Elliott \& Wehrly 2005).

Mais de 50 anos depois de Saint-Hilaire, o biólogo e naturalista alemão Fritz Müller ${ }^{1}$, que viveu grande parte de sua vida em Blumenau, Santa Catarina, publicou em 1877, na Alemanha, o artigo intitulado "Der Minhocão". Nesse artigo, Müller descreve, também a partir dos relatos de testemunhas, os feitos de minhocas gigantescas, com 2 a 3 metros de diâmetro e 25 metros de comprimento. Estes animais apareciam após longos períodos chuvosos e cavavam trincheiras e buracos no solo, formando grandes canais que desviavam o curso de riachos, provocavam a queda de árvores, o secamento de banhados e turvamento de rios. Mesmo considerando pouco confiáveis as informações sobre o minhocão, o naturalista fez uma ilação análoga a de seu antecessor, ao supor tratar-se de um gigantesco peixe pulmonado à semelhança do Lepidosiren e Ceratodus (Zillig 1997).

Apesar de essas histórias serem contadas em muitos locais distintos do território brasileiro, a água parece ser o elemento mais recorrente em todas elas. De forma geral, o minhocão do Rio São Francisco é o personagem símbolo de todas as sociedades lacustres brasileiras (Lins 1983). Entretanto, embora haja semelhanças também em alguns aspectos comportamentais do animal, sua descrição muda drasticamente em cada lugar, assumindo, muitas vezes, características prodigiosas e extravagantes.

No próprio Rio São Francisco o minhocão é por vezes descrito pelos barqueiros como uma serpente gigantesca, fluvial e subterrânea, cujo movimento sob o solo abala a estrutura das cidades e provoca o desmoronamento de roças e casas próximas às margens. $\mathrm{O}$ animal também poderia assumir a forma de um peixe surubim (ou surubim-rei) de tamanho descomunal (Pardal 1979) ou ainda de um grande pássaro branco, mas com o pescoço fino e comprido, lembrando uma minhoca (Cascudo 1984).

De fato, sabe-se que alguns minhocuçus podem causar desmoronamentos de terra em áreas de solos humíferos rasos sobre rochas, como foi reportado, por exemplo, para a espécie Fimoscolex sacii (Righi 1971) na serra do mar em São Paulo (Righi 1997). Também se suspeita que elas possam causar o vazamento de represas, como foi reportado para a espécie Andiorrhinus samuelensis (Righi 1986) na represa de Samuel, RO (Righi 1990), ou ainda o escoamento de água de valas de drenagem (Righi 1997).

\footnotetext{
${ }^{1}$ Fritz Müller foi o primeiro a descrever a espécie de minhoca Pontoscolex corethrurus no Brasil, hoje tida como uma das de maior dispersão no território nacional (Brown et al. 2006).
} 
No período colonial, o Rio São Francisco foi um fator decisivo da unidade territorial do país que se construía, exercendo da mesma forma uma grande influência na unidade de suas lendas, mitos e crenças populares. As lendas européias sobre monstros e outros seres marinhos vindas com os colonizadores, assim como os seres e animais noturnos de várias áreas do sertão e do interior do Brasil, aos poucos foram sendo incorporadas ao patrimônio cultural do rio, dando origem a uma mitologia colorida, tal como a que se conhece hoje (Lins 1983).

A superstição encontra campo fértil no São Francisco, onde as condições de vida ainda são penosas. A ingenuidade de seus moradores busca explicações sobrenaturais para as coisas que os aterrorizam, em especial os perigos do rio, como os encalhes, naufrágios e afogamentos (Pardal 1979).

No outro extremo do Brasil, no Rio Grande do Sul, o 'mito do minhocão' também aparece e exibe formas extraordinárias. Na Lagoa do Armazém, em Tramandaí, o minhocão é descrito como uma espécie de serpente monstruosa de origem marinha, muito grande, com olhos e língua de fogo verde e pêlos na cabeça, que vira embarcações e come porcos e galinhas nas margens (Radar-RS 2008). Já em Salto do Jacuí, o minhocão possui 12 metros de comprimento, 1,20 metros de largura, nunca sai da água e, inclusive, tem filhotes (Rota das Terras 2008).

Porém, é no Estado de Mato Grosso que o 'mito do minhocão' parece, ainda hoje, estar presente no cotidiano das pessoas, não apenas no imaginário popular, mas também como um forte elemento de identidade cultural de seu povo. Esse fato se revela nas manifestações de orgulho que têm composto a cena cultural do estado nos últimos anos, com a publicação de livros (Rodrigues 1985, Sigrist 2000), encenações de teatro (Confraria dos Atores 2008), produção de material para trabalhos em educação ambiental e inclusive desenho animado ${ }^{2}$, nos quais o mito é recontado para as gerações mais jovens.

Assim como em outros lugares, o 'mito do minhocão' no Mato Grosso também apresenta variações, estando mais presente no imaginário dos habitantes do pantanal e das margens do Rio Cuiabá. Em alguns casos é relatado como uma serpente monstruosa, que perambula pelos rios e águas do Pantanal virando canoas, devorando pescadores, levantando grandes ondas e desmoronando barrancos dos rios. Na cidade de Cáceres, a história assume ainda contornos religiosos. A construção da Catedral de São Luis foi iniciada em outubro de 1919, porém, em fevereiro de 1949, toda a estrutura interna do prédio desabou, comprometendo o projeto e retardando sua inauguração, que só veio a acontecer em agosto de 1965 (Cáceres 2008). Segundo o imaginário popular, o desabamento se deu por conta dos movimentos do 'minhocão', que atualmente está preso por fios de cabelo de Nossa Senhora sob a catedral. Para

\footnotetext{
${ }^{2}$ Uma adaptação da lenda original do minhocão no estado do Mato Grosso, do diretor Marcelo Okamura, pode ser visualizada em animação no endereço <http://www.mto2.com.br/minhoca/index.htm>. Acesso em: 18 janeiro 2008.
} 
evitar que esses fios se rompam e libertem novamente o minhocão, a catedral não pode ser reformada ou restaurada (Veredas Brasil 2008).

Um trabalho realizado em duas pequenas comunidades no Pantanal Matogrossense investigou a percepção fenomenológica das pessoas, do meio rural e urbano, sobre o 'mito do minhocão' (Garcia \& Sato 2006). Durante as entrevistas qualitativas eram mostradas às pessoas seis iconografias com diversas percepções a respeito do minhocão, variando desde uma minhoca gigantesca (porém morfologicamente real) abrindo sulcos na terra até uma serpente monstruosa dentro do rio ao lado de uma embarcação. Dos dezesseis entrevistados, $37,5 \%$ identificaram a figura da grande minhoca como sendo o minhocão, outros $18,8 \%$ como sendo o monstro em forma de serpente, $12,5 \%$ como uma sucuri e os demais se distribuíram entre as outras imagens ou não identificaram nenhuma das representações como sendo o 'minhocão'.

Não há como negar a existência de minhocas gigantes, com dimensões muito superiores às que são costumeiramente observadas na natureza. A primeira minhoca a ser descrita no Brasil foi um exemplar com mais de um metro de comprimento, da espécie Glossoscolex giganteus, por Leuckart em 1836, no Rio de Janeiro (James \& Brown 2006). Já a maior minhoca coletada no país foi um exemplar da espécie Rhinodrilus fafner, com 2,1 metros de comprimento, capturada próxima à cidade de Belo Horizonte, Minas Gerais (Michaelsen 1918). Contudo, nunca houve o registro científico de uma espécie de minhoca como aquelas descritas em "Der Minhocão" de Fritz Müller ou em qualquer outro relato (James \& Brown 2006).

No espaço do real surgem, porém, algumas explicações para a existência do mito. $\mathrm{O}$ forte estrondo de um barranco desmoronando na água, carregando consigo grandes árvores, parte das roças, casas próximas e animais desavisados, num local onde momentos antes prevaleciam os suaves sons da natureza, pode ser, de fato, uma visão impressionante. Para os ribeirinhos isso só pode ser obra de um ser fantástico como o 'minhocão', mas numa percepção menos mítica, nada mais é do que a ação da erosão provocada pelas ondas dos barcos dos pescadores (Bomediano 2008). O desmatamento provocado nas margens dos rios, com intuito de ampliar áreas agricultáveis ou de pastagens, também pode ser outra explicação bastante razoável para o desmoronamento dos barrancos.

Na cidade de Espumoso, no Rio Grande do Sul, um minhocão que habita as proximidades da Ilha do Pançudo no Rio Jacuí seria, segundo a explicação de alguns moradores, apenas uma história inventada pelos pais para assustar os filhos que, nos dias quentes, iam se banhar no rio, e assim mantê-los afastados dos locais perigosos para evitar afogamentos. Isso explicaria, inclusive, a maior freqüência de aparições do "minhocão do Pançudo" justamente nos meses de verão (Heuser 2006).

Em muitas das narrativas, as ações provocadas pelo minhocão são contraditórias quanto ao seu objetivo. Às vezes, a criatura é retratada como violenta e assassina (Cascudo 1984, Tom do Pantanal 2008), em outras como um ser vingativo (Rota das 
Terras 2008) ou ainda apenas como um ser que disputa espaço ecológico com os outros animais, que não tem maldade e nem deseja prejudicar o homem (Bomediano 2008).

Independentemente de sua representação, como monstro, cobra ou minhoca, outro tema que também é muito recorrente nas justificativas de suas ações é a questão ambiental. No pantanal, por exemplo, os participantes da pesquisa afirmaram que o 'minhocão' apenas ataca aqueles que agridem a natureza, os que poluem as águas e os pescadores que pescam com rede (Garcia \& Sato 2006). É essa, também, a visão que tem sido reforçada no resgate do mito do 'minhocão' nos trabalhos de educação ambiental desenvolvidos no Mato Grosso.

\section{CONCLUSÕES}

É pouco provável que um dia se saiba, com certeza, a real origem da palavra 'minhoca', até porque muitos dos textos de referência mais recentes parecem ter optado por classificá-la como obscura ou controversa. São apresentadas, aqui, algumas das possibilidades encontradas, cabendo a cada um a escolha que julgar mais científica, plausível ou romântica, ou até mesmo nenhuma.

Um aspecto que se revela interessante no 'mito do minhocão' é o vínculo formado entre o nome que é dado à criatura e a sua forma mais tradicional, de cobra ou serpente. Uma análise antropológica ou sociológica mais profunda poderia buscar seus reais significados, mas não se pode deixar de observar as próprias teorias a respeito da origem da palavra 'minhoca'. Seja a partir de 'nyoka' ou 'aboy' (derivado de 'mboy'), a 'cobra' sempre foi um elemento presente na representação da minhoca pelas culturas africanas e indígenas. E da mesma forma, o paradoxo entre o ser perverso e o ser defensor da natureza, pode, sob certo ponto, estar embutido nessa dicotomia comportamental, que por vezes reflete o próprio ser humano: às vezes Dr. Jekyll, outras Mr. Hyde, do famoso livro de Robert Louis Stevenson ${ }^{3}$.

Seja como for, o que não se pode ignorar é o legado cultural que povos inteiros deixaram registrados, oral e graficamente, a respeito de um ser tão comum e, ao mesmo tempo, tão fascinante para a ciência. Cabe também à ciência garantir a perpetuação desse legado.

\section{AGRADECIMENTO}

Ao Conselho Nacional de Apoio à Pesquisa - CNPq

\section{LITERATURA CITADA}

Alpers, E. A. 2005 'Mozambiques' in Brazil: another dimension of the African diaspora in the Atlantic world. Pp. 43-68. In: J.C. Curto and R. Soulodre-LaFrance (Eds). Africa and the Americas: interconnections during the slave trading. Africa World Press, Ontário.

3 "Dr. Jekyll and Mr. Hyde", no Brasil traduzido como "O médico e o monstro". 
Barahona, R. 1987. Conocimiento campesino y sujeto social campesino. Revista Mexicana de Sociología. 49: 167-190.

Bomediano, D. F. 2008. Rio Cuiabá. Fishpoint. http://www.fishpoint.com.br/novo/dfb1.htm.

Brown, G. G. \& S. W. James. 2007. Ecologia, biodiversidade e biogeografia das minhocas no Brasil. Pp. 297-381. In: G. G. Brown and C. Fragoso C (Eds.) Minhocas na América Latina: biodiversidade e ecologia. Embrapa Soja, Londrina.

Brown, G. G., S. W. James, A. Pasini, D. H. Nunes, N. P. Benito, P. T. Martins \& K. D. Sautter. 2006. Exotic, peregrine and invasive earthworms in Brazil: diversity, distribution and effects on soils and plants. Caribbean Journal of Science. 42: 339-358.

Bueno, E. 2006. A viagem do descobrimento v.1. Editora Objetiva, Rio de Janeiro.

Bueno, F. da S. 1974. Grande dicionário etimológico-prosódico da Língua Portuguesa. 5.v. Editora Brasília Limitada, Santos.

Bueno, S. 1987. Vocabulário tupi-guarani-português. 5.ed. Brasileiros Editora, São Paulo.

Cascudo, L. da C. 1984. Dicionário do folclore brasileiro. 5.ed. Editora Itatiaia Ltda, Belo Horizonte.

Cascudo, L. da C. 2001. Antologia do folclore brasileiro. 5.ed. Global, São Paulo.

Cáceres. 2008. A cidade: atrativos naturais e turísticos - Catedral de São Luis. http://www.caceres. mt.gov.br.

Chaia, N. P. 2006. Cultura Bantu. Línguas minoritárias. http://www.uaisites.adm.br.

Confraria dos atores. 2008. Confraria dos atores. http://confrariadosatores.blogspot.com.

Cunha, A. G. da. 1986. Dicionário etimológico Nova Fronteira de língua portuguesa. 2 ed. Nova Fronteira, Rio de Janeiro.

Dooley, R. A. 2006. Léxico guarani, dialeto mbyá. Sociedade Internacional de Lingüística. www.sil. org/americas/BRASIL/PUBLCNS/DICTGRAM/GNDicLex.pdf.

Elliott, S. \& K. Wehrly. 2005. Lepidosiren paradoxa: South American lungfish. University of Michigan Museum of Zoology. http://animaldiversity.ummz.umich.edu.

Feller, C., G. G. Brown, E. Blanchart, P. Deleporte \& I. S. Chernyanski. 2003. Charles Darwin, earthworms and the natural sciences: various lessons from past to future. Agriculture Ecosystems \& Environment. 90: 29-49.

Ferreira, A. B. de H. 2004. Novo dicionário eletrônico Aurélio versão 5.0. Editora Positivo. Curitiba. CD-ROM.

Fragoso, C., G. G. Brown, J. C. Patrón, E. Blanchart, P. Lavelle, B. Pashanasi, B. Senapati \& T. Kumar. 1997. Agricultural intensification, soil biodiversity and agroecosystem function in the tropics: the role of earthworms. Applied Soil Ecology. 6: 17-35.

Furtado, N. F. 1969. Vocábulos indígenas na geografia do Rio Grande do Sul. PUC, Porto Alegre.

Garcia, D. A. \& M. Sato. 2006. Mitos e lendas na identidade cultural pantaneira: subsídios à educação ambiental. Revista da Educação Pública. 29:41-57.

Heuser, P. R. 2006. Minhocão do pançudo. Crônicas do Heuser. http://pauloheuser.blogspot. com/2006/05/minhoco-do-panudo.html.

Houaiss, A., M. de S. Villar \& F. M. de M. Franco (Eds.). 2007. Dicionário eletrônico Houaiss da lingua portuguesa versão 2.0. Editora Objetiva, Rio de Janeiro. CD-ROM.

Instituto Socioambiental. 2008. Povos indígenas no Brasil. Instituto Socioambiental. http://www.socioambiental.org/pib/index.html

James, S. W. \& G. G. Brown. 2006. Earthworm ecology and biodiversity in Brazil. Pp. 56-116. In: F. M. S. Moreira, J. O. Siqueira and L. Brussaard. (Eds.) Soil biodiversity in Amazonian and other Brazilian ecosystem. CAB International, Wallingford.

Katulembe, F. 2008. Palavras de origem bantu inseridas no português. Kimbundu HP. http://www. linguakimbundu.com. 
Schiedeck et al.: Aspectos culturais das minhocas no Brasil

Koehler, H. 1959. Dicionário escolar latino-português. Editora Globo, Porto Alegre.

Larousse cultural. 1999. Grande dicionário da língua portuguesa. Nova Cultural, São Paulo.

Lins, W. 1983. O médio São Francisco: uma sociedade de pastores e guerreiros. 3 ed. Companhia Editora Nacional/Instituo Nacional do Livro, São Paulo.

Lipski, J. M. 2008a. Angola e Brasil: vínculos linguísticos afro-lusitanos. The Pennsylvania State University. http://www.personal.psu.edu/jml34/ang-bras.pdf

Lipski, J. M. 2008b. Os primeiros contatos afro-portugueses: implicações para a expansão da língua. The Pennsylvania State University. http://www.personal.psu.edu/jml34/contatos.pdf

Medeiros, A. A. D. de. 2008. A língua portuguesa. Universidade federal do Rio Grande do Norte. http://www.linguaportuguesa.ufrn.br.

Michaelsen, W. 1918. Die Lumbriciden. Zoologische Jahrbucher Abteilung für Systematik. 41: 1-398.

Minnich, J. 1977. The earthworm book: how to raise and use earthworms for your farm and garden. Rodale Press, Bethlehem.

Moreno, A. G. \& M. G. Paoletti. 2004. Andiorrhinus (Andiorrhinus) kuru sp. nov. (Oligochaeta: Glossoscolecidae), a giant earthworm as food resource for Makiritare Indians of the Alto Rio Padamo, Amazonas, Venezuela. Canadian Journal of Zoology. 82: 1000-1004.

Museu do Índio. 2008. Dicionário básico. Funai. http://base.museudoindio.org.br.

Navarro, E. 2008. Vocabulário tupi-português das lições. Curso de tupi antigo. Universidade de São Paulo. http://www.fflch.usp.br/dlcv/tupi/vocabulario.htm.

Nicolai, R. 2008. Vocabulário/Dicionário de tupinambá, tupi antigo, língua brasílica e abañeenga do Norte. Línguas indígenas brasileiras. http://www.indios.info.

Paoletti, M. G. \& D. L. Dufour. 2005. Edible invertebrates among Amazonian Indians: A critical review of disappearing knowledge. Pp. 289-338. In: M.G. Paoletti. (Ed.). Ecological implications of minilivestock: potential of insects, rodents, frogs and snails. Science Publishers, Enfield.

Pardal, P. 1979. Carrancas do São Francisco. Funarte, Rio de Janeiro.

Pinto, A. O. 2008. Vocabulário kimbundu-português. Centro de Estudos Multiculturas - Estudos Angolanos. http://multiculturas.com/angolanos/alberto pinto kimb port vocab.htm.

Radar-RS. 2008. Lendas gaúchas: a lenda do minhocão. http://www.lendas-gauchas.radar-rs.com.br/ a_lenda_do_minhocao.htm.

Ramos, R. 1997 . A língua kimbundu. Ciberdúvidas da Língua Portuguesa. http://ciberduvidas.sapo. pt/diversidades.php?rid=351

Righi, G. 1971. Sôbre a Família Glossoscolecidae (Oligochaeta) no Brasil. Arquivos de Zoologia, São Paulo. 20: 1-96.

Righi, G. 1990. Minhocas de Mato Grosso e de Rondônia. Programa Polonoroeste, Relatório de Pesquisa ${ }^{\circ}$ 12. SCT/PR-CNPq, Programa do Trópico Úmido, Brasília.

Righi, G. 1997. Minhocas da América Latina: diversidade, função e valor. In: Anais do XXVI Congresso Brasileiro de Ciência do Solo. Rio de Janeiro. SBCS, Rio de Janeiro. CD-Rom.

Righi, G. 1998. Earthworms of the Ilha de Maracá. Pp. 391-397. In: W. Milliken and J. Ratter. (Eds). Maracá: the biodiversity and environment of an Amazonian rainforest. John Wiley \& Sons. Chichester.

Righi, G. \& Y. Araújo. 1999. Andiorrhinus (Amazonidrilus) motto n. sp. and Rhinodrilus appuni pavoni $\mathrm{n}$. subsp. (Oligochaeta, Glossoscolecidae) from the Venezuelan Amazonia. Miscelanea Zoologica. 22: 93-100.

Righi, G. \& A. T. Guerra. 1985. Alguns Oligochaeta do norte e noroeste do Brasil. Boletim de Zoologia. 9: 145-157.

Rocha, E. 1996. O que é mito. $7^{\mathrm{a}}$ ed. Brasiliense, São Paulo.

Rodrigues, D. 1985. Roteiro das lendas.UFMT, Cuiabá. 
Rota das terras. 2008. Salto do Jacuí: cultura - o minhocão. http://www.rotadasterras.com.br.

Sigrist, M. 2000. Chão batido: a cultura popular do Mato Grosso do Sul. Editora da UFMS, Campo Grande.

Silva, E. L. da. 2008. Pequeno dicionário tupi-guarani de um manezinho. Universidade Federal de Santa Catarina. www.ufsc.br/ esilva/Dicionario.html.

Toledo, V. M. 1991. El juego de la supervivencia: un manual para la investigación etnoecológica en Latinoamerica. CLADES, Santiago.

Torrinha, F. 1986. Dicionário latino português. 3 ed. Gráficos Reunidos, Porto.

Tunes, S. 2008. O tupi ressurge em páginas de livros, telas de cinema e pode chegar às salas de aula. Curso de Tupi antigo. Universidade Federal de São Paulo. http://www.fflch.usp.br.

Veredas Brasil. 2008. Pantanal: histórias-lendas. http://www.veredasbrasil.com.br.

Victoria, L. A. P. 1958. Dicionário da origem e da evolução das palavras. Editora Científica, Rio de Janeiro.

Zillig, C. 1997. Dear Mr. Darwin: a intimidade da correspondência entre Fritz Muller e Charles Darwin. Sky/Anima Comunicação e Design, São Paulo. 